\title{
A comparative study to identify factors of caregiver burden between baby boomers and post baby boomers: a secondary analysis of a US online caregiver survey
}

Heejung Kim ${ }^{1,2}$, Sangeun Lee ${ }^{1}$, Jooyoung Cheon ${ }^{3 *}$, Soyun Hong ${ }^{1}$ and Mido Chang ${ }^{4}$

\begin{abstract}
Background: Baby boomers' position in the caregiving context is shifting from caregiver to care recipient as the population ages. While the unique characteristics of baby boomer caregivers are well established in caregiving literature, there is limited information about the next caregiving group after the baby boomers. In this study, the sociodemographic and caregiving-related characteristics of the two generations are compared and specific factors contributing to caregiver burden between baby boomer and post baby boomer caregivers are identified.

Methods: This cross-sectional and correlational study used secondary analysis of data from the National Alliance for Caregiving and the American Association of Retired Persons. A structured online survey was conducted in 2014 with randomly selected samples $(n=1069)$ in the United States focusing on sociodemographics, caregiving-related characteristics, and burden of care. Descriptive statistics, multivariate linear regression analyses, and Steiger's Z-test were used to identify group differences in multivariate factors related to caregiver burden in two generational groups.

Results: Baby boomers and post baby boomers experienced caregiver burden to a similar degree. Caregiving-related factors are more likely to increase burden of care than sociodemographics in both groups. Caregiving without choice and spending longer hours on caregiving tasks were common factors that increased the burden in both generational groups (all $p$ values $<0.01$ ). However, post baby boomer caregivers reported additional challenges, such as unemployment during caregiving, the dual responsibility of both adult and child care, and a family relationship with the care recipient.

Conclusions: Due to the aging population of baby boomers, post baby boomers encounter different challenges related to caregiving burden, which is often considered an additional workload in their life course. Current policy and program tailored to baby boomers should be re-designed to meet the different needs of emerging caregivers. Specific vulnerable subgroups should have priority to receive the benefits of specific policies, such as those without choice and younger, working caregivers.
\end{abstract}

Keywords: Caregiver burden, Age, Baby boomers, Post baby boomers, National Alliance for Caregiving, Secondary data analysis

\footnotetext{
* Correspondence: jcheon@sungshin.ac.kr

${ }^{3}$ College of Nursing, Sungshin Women's University, 55 Dobong-ro 76ga-gil,

Gangbuk-gu, Seoul 01133, South Korea

Full list of author information is available at the end of the article
}

(c) The Author(s). 2018 Open Access This article is distributed under the terms of the Creative Commons Attribution 4.0 International License (http://creativecommons.org/licenses/by/4.0/), which permits unrestricted use, distribution, and reproduction in any medium, provided you give appropriate credit to the original author(s) and the source, provide a link to the Creative Commons license, and indicate if changes were made. The Creative Commons Public Domain Dedication waiver (http://creativecommons.org/publicdomain/zero/1.0/) applies to the data made available in this article, unless otherwise stated. 


\section{Background}

Informal caregiving is more important than ever because of an aging population, increasing healthcare expenditures, and the lifelong impact of chronic diseases. In 2013, seven developed countries established the International Alliance of Carer Organizations to advocate for caregivers' health and to acknowledge their values. The priority action in their strategic plan is to increase awareness of caregiving, with a focus on who caregivers are and what they do worldwide [1]. As a unique cohort due to the cultural shift and historical background [2, 3], baby boomer caregivers provide more and longer caregiving for aging parents than ever before as life expectancies increase. In addition, they continue to support their grown children financially, even in adulthood [4-9]. However, baby boomers' position in the caregiving context is shifting from caregiver to care recipient $[3,7]$ because they are aging as a population [10], with high demands on their own health $[4,5]$. In 2015, average ages of informal caregivers and care recipients in the U.S. were 49 and 69 years old, respectively, which indicates that the next generation after baby boomers are expected to play a critical role in informal caregiving.

Caregiving provided by post baby boomers is expected to be different from that of previous generations because of change of culture and family systems. Post baby boomer caregivers were born into smaller families because of the introduction of contraceptives and grew up in a time when divorce rates were high $[11,12]$. Their mothers worked outside the home more compared to the mothers of earlier generations, which led to them being called "latchkey children" [11, 12]. Parent-child relationships among post baby boomers are weaker than parent-child relationship among baby boomers because of parents' divorces, remarriages, and multipartnerships $[12,13]$.

Although the unique characteristics of baby boomer caregivers are well established in terms of their health problems, financial hardships, and role perceptions [5, 6, 14], healthcare providers and policy makers have paid less attention to upcoming caregivers who will care for baby boomers. Baby boomers might expect high levels of informal caregiving because they have provided their offspring strong support $[9,15]$. However, there is limited information on the next caregiving group after the baby boomer generation $[9,11,14]$. Only two studies have examined generation differences between baby boomers and post baby boomers; however, they examined generational differences in self-rated health [16] and work-family conflict [17].

In addition, caregivers need to perform diverse roles across the life span in terms of family-work balance [18]. Different factors of increasing burden of care seem to be associated with levels of family involvement, caregiving duties, and different challenges caregivers encounter at specific points in their lifespan [19-21]. Younger caregivers want to be more active when participating in social activities, enjoying leisure, or performing working tasks compared to older caregivers, while older caregivers feel responsible for prioritizing the caregiving role rather than their social roles [20, 22]. However, it is questionable whether this trend will continue, because of baby boomers' unique characteristics in pursuing independence, autonomy, and strong healthcare needs $[4,5]$. Moreover, most previous studies examined informal caregivers of persons living with specific diseases, such as dementia [23] and cancer [24], thus it is difficult to apply study findings to the overall caregiving population [23-25]. Therefore, the objectives of this study are to examine the sociodemographic and caregivingrelated differences between baby boomer caregivers and post baby boomer caregivers and to compare the contributing factors to caregiver burden between two generations.

\section{Methods \\ Design}

This cross-sectional, correlational study incorporated secondary data analysis of the National Alliance for Caregiving (NAC) and the American Association of Retired Persons (AARP) [2] database.

\section{Samples and procedure of secondary data analysis}

For the secondary data analysis, an exempt status was obtained through the Institutional Review Board based on the use of de-identifiable data. Informal caregivers were defined as persons providing unpaid care or assistance based on needs or performing housework for those whom the respondent knew [4]. To compare two generational groups of caregivers, we categorized baby boomers born between 1946 and 1964 and post baby boomers born after 1964 using the U.S. nationally representative samples. In the primary data of the NAC and AARP survey, a nationally representative sample in the U.S. $(N=7660)$ was selected based on (1) a random selection of telephone numbers and residential addresses and (2) oversampling of racial and ethnic minority groups [26]. The analysis included 1069 persons after excluding those who did not meet eligibility criteria (see Fig. 1).

For primary data collection in the NAC and AARP survey, a standardized online questionnaire was administered via a computer-aided Web interviewing system, in English or Spanish, in September 2014 after obtaining informed consent [26]. The variables for this secondary data analysis were selected from the 2015 NAC and AARP data according to Pearlin's Stress Process model (see Fig. 2) [27]. First, caregivers' sociodemographics included age, gender, race/ethnicity, marital status, a relationship to the care recipient, education, co-resident 


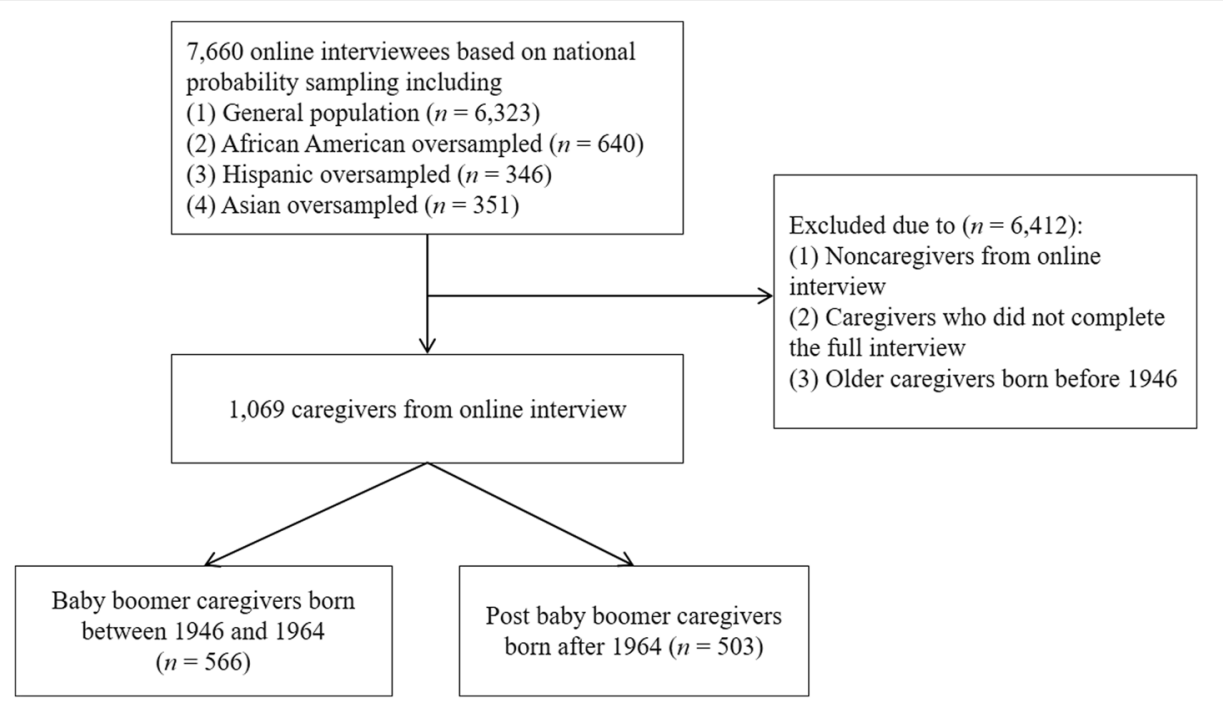

Fig. 1 Flowchart of samples describes how to reach the final sample $(n=1069)$ samples (unweighted) from 7660 online interviewees

status with care recipients, annual household income, and residence area. Household income was dichotomized based on U.S. $\$ 50,000$ per year, which is considered the median income level [28]. Second, information on caregiving included (1) caregiving hours spent on care recipients per week, (2) current caregiving during the past 12 months, (3) primary caregiving with or without secondary caregivers, (4) lack of choice to take the caregiving role, (5) employment during caregiving, and
(6) dual responsibility for both adult and child care. Third, self-reported caregiver burden consisted of three items-physical strain, emotional stress, and financial hardship-as the previous studies used to assess the health of caregivers more comprehensively [14, 15]. Each item was measured on a 5 -point Likert scale $(1=$ not at all a strain/stressful/hardship; $5=$ very much a strain/ stressful/hardship). A composite score was computed with the mean of the three items, consistent with the

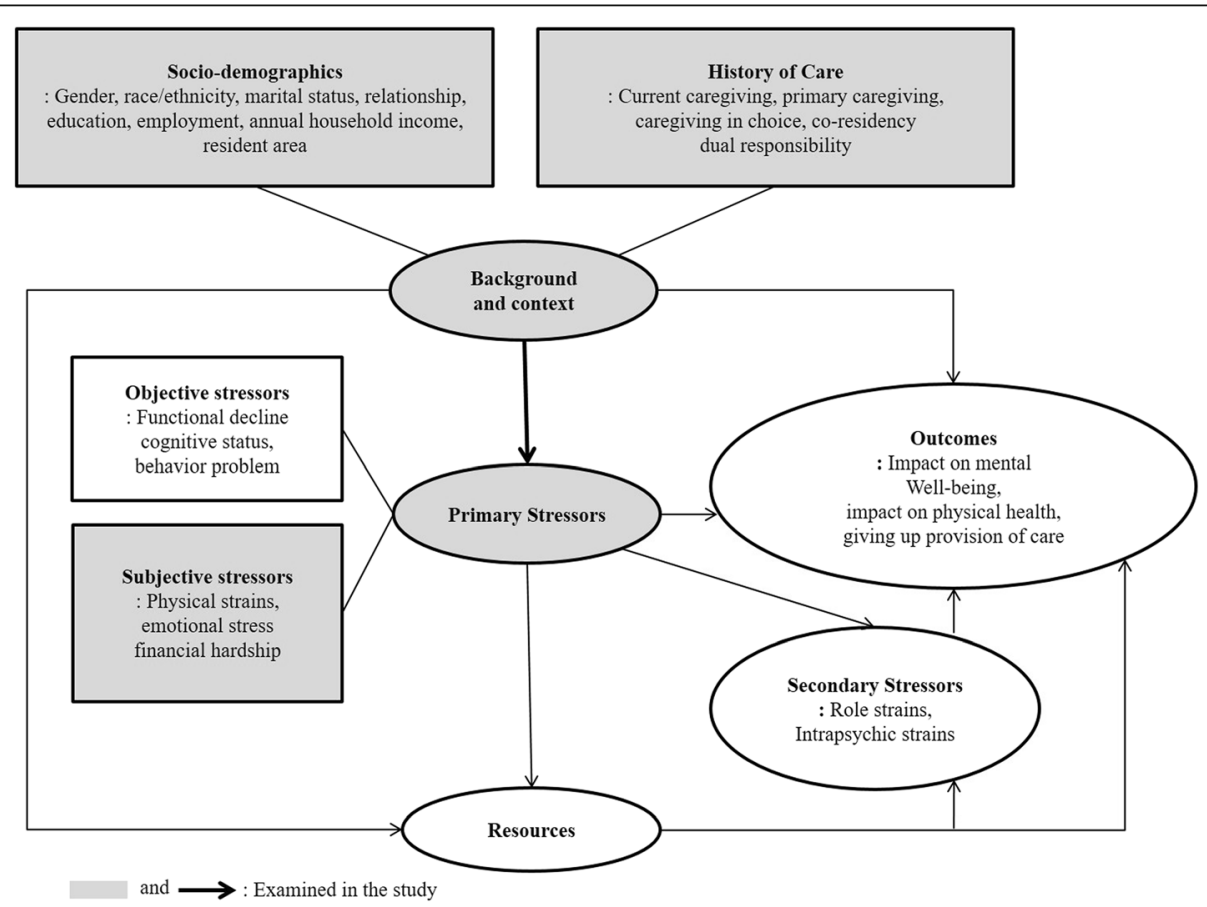

Fig. 2 Conceptual framework of Pearline's stress process model shows a modified model that guided variable selection and interpretation of the study findings 
NAC and AARP report and a previous study [29] (Cronbach's alpha $=0.73$ ).

\section{Analysis}

Descriptive statistics included means with standard deviations and weighted percentages. Independent $\mathrm{t}$-tests (or Mann Whitney U-tests) and $\chi^{2}$-tests were used to compare sociodemographic and caregiving characteristics between two groups. Multivariate linear regression and Fisher's and Steiger's Z-tests [30] were used to identify and compare significant predictors of caregiver burden between the two groups. The $\mathrm{Z}$-test is computed as $\left(\mathrm{Z}_{1}-\mathrm{Z}_{2}\right) /$ $\mathrm{SE}_{\mathrm{ZD}}$ and $\mathrm{SE}_{\mathrm{ZD}}=$ squared root of $[1 /(\mathrm{n} 1-3)+1 /(\mathrm{n} 2-3)]$. The number of hours of caregiving per week was transformed using a natural $\log$ function considering univariate normality. There was no concern regarding (1) linearity between caregiving burden and the transformed variable of the number of hours of caregiving per week and (2) multicollinearity among independent variables. All statistical analyses were performed using IBM SPSS 23.0 with the significance level set at .05, two-tailed. A single-stage population weighting was used to increase generalizability of the study findings to national caregivers at the population level. The population weighting was based on information of initially screened and randomly selected respondents. Each score was calculated based on age, sex, and race/ethnicity information extracted from the 2014 Current Population Survey conducted by the U.S. Census Bureau [26].

\section{Results}

Sociodemographic differences between baby boomer and post baby boomer caregivers

The average age of the caregivers was $42.25(S D=13.78)$ and ranged from 18 to 68 . The average age in the baby boomer group was $57.90(S D=5.28)$, while that in the post baby boomer group was $34.75(S D=9.00)$. The majority of caregivers were female, non-Hispanic Caucasian, married or partnered, had more than a high school education, were employed, and lived in urban areas. Half of the caregivers had an annual household income of more than $\$ 50,000$ and were the care recipient's child or grandchild (see Table 1). Compared to post baby boomer caregivers, baby boomer caregivers were likely to be non-Hispanic Caucasian, married or living with a partner, and living with more household income than $\$ 50,000$ per year $(p \leq 0.01)$. Employment during caregiving was lower in the baby boomer group than in the post baby boomer group $\left(\chi^{2}=11.34, p<0.01\right)$. Baby boomer and post baby boomer caregivers were the care recipients' child or

Table 1 Comparison of sociodemographic characteristics of informal caregivers in the two generational groups

\begin{tabular}{|c|c|c|c|c|c|c|}
\hline Variables & Levels & All (weighted \%) & $\begin{array}{l}\text { Baby boomer group } \\
\text { (weighted \%) }\end{array}$ & $\begin{array}{l}\text { Post baby boomer group } \\
\text { (weighted \%) }\end{array}$ & $x^{2}$ & $p$ value \\
\hline \multirow[t]{2}{*}{ Gender } & Male & 40.94 & 38.45 & 43.01 & 2.24 & 0.15 \\
\hline & Female & 59.06 & 61.55 & 56.99 & & \\
\hline \multirow[t]{4}{*}{ Race/ethnicity } & NH Caucasian & 59.36 & 71.10 & 49.65 & 51.19 & $<0.001$ \\
\hline & $\mathrm{NH}$ African American & 13.48 & 9.49 & 16.78 & & \\
\hline & Hispanic & 18.36 & 12.03 & 23.60 & & \\
\hline & $\mathrm{NH}$ Asian or others & 8.80 & 7.38 & 9.97 & & \\
\hline \multirow[t]{2}{*}{ Marital status } & Married or partnered & 65.01 & 69.51 & 61.25 & 7.66 & 0.01 \\
\hline & No partner & 34.99 & 30.49 & 38.75 & & \\
\hline \multirow[t]{5}{*}{ Relation to the care-recipient } & Spouse or partner & 8.03 & 10.55 & 5.95 & 37.20 & $<0.01$ \\
\hline & Parents or grandparents & 4.11 & 7.59 & 1.22 & & \\
\hline & Child or grandchild & 54.49 & 50.21 & 58.04 & & \\
\hline & Other relative & 19.41 & 19.41 & 19.41 & & \\
\hline & Non-relative & 13.96 & 12.24 & 15.38 & & \\
\hline \multirow[t]{2}{*}{ Education } & Up to high school & 35.11 & 34.74 & 35.43 & 0.05 & 0.85 \\
\hline & College level or higher & 64.89 & 65.26 & 64.57 & & \\
\hline \multirow[t]{2}{*}{ Co-residence } & Live with care-recipients & 32.75 & 31.06 & 34.16 & 1.12 & 0.32 \\
\hline & Live separately & 67.25 & 68.94 & 65.84 & & \\
\hline \multirow[t]{2}{*}{ Household poverty } & Less than $\$ 50,000$ & 46.70 & 40.21 & 52.10 & 14.73 & $<0.01$ \\
\hline & More than $\$ 50,000$ & 53.30 & 59.79 & 47.90 & & \\
\hline \multirow[t]{2}{*}{ Residence area } & Urban & 84.73 & 83.16 & 86.04 & 1.67 & 0.23 \\
\hline & Rural & 15.27 & 16.84 & 13.96 & & \\
\hline
\end{tabular}


grandchild; however, baby boomers were more likely to be a spouse or parent of the care recipient $\left(\chi^{2}=37.20\right.$, $p<0.01)$. There were no significant differences in gender, education, and residential area between the two generational groups.

\section{Caregiving-related differences in two caregiving groups}

Caregivers spent an average of $24.42(S D=29.18)$ hours weekly on caregiving. The baby boomer group spent $4 \mathrm{~h}$ more on caregiving $(\mathrm{M}=25.76, \mathrm{SD}=29.43)$ than the post baby boomer group $(\mathrm{M}=21.73, \mathrm{SD}=27.69, p<0.01)$. Baby boomers reported higher levels of caregiver burden $(M=2.64, S D=1.03)$ compared to post baby boomers $(M=2.56, S D=1.04, p<0.04)$. Both generational groups were currently providing caregiving, living separately from the care recipient, and taking care of adult care recipients only; however, these tendencies were stronger in baby boomer caregivers than in post baby boomer caregivers. Post baby boomers were likely to be primary caregivers rather than secondary caregivers, but they chose to be caregivers based on their own decision. Caring for both adult and child recipients was significantly higher in the post baby boomers $(22.90 \%)$ compared to the baby boomer group $\left(6.95 \%, \chi^{2}=50.00, p<0.001\right.$, see Table 2$)$.

\section{Model comparison of caregiver burden between two generational groups}

As shown in Table 3, the model of caregiver burden for baby boomers significantly explained $18 \%$ of the variance, which was lower than $21 \%$ in the model for the post baby boomers $(p<0.001)$ after controlling for age. In both generational groups, caregiving-related characteristics (Block 2) explained 2.5 times as much of the variance in caregiver burden as sociodemographic characteristics (Block 1). A comparison of the two generational groups was conducted by applying the model derived from the baby boomer group (direct $R^{2}=0.44$ ) to the data from the post baby boomer group (crossed
$\left.R^{2}=0.44\right)$. However, two models were not statistically different $(Z=1.16, p=0.25)$.

After controlling for caregivers' socio-demographic characteristics including age, caregiving without choice was identified as the most significant factor between the two generational groups $(\beta=0.29$ in baby boomer group and $\beta=0.31$ in the post baby boomer group, $p<0.01$ ) to similar degrees $(Z=-0.47, p=0.32)$. The number of hours of caregiving was another common factor contributing to caregiver burden in both generational groups $(\beta=0.26$ in the baby boomer group and $\beta=0.16$ in the post baby boomer group, $p<0.01$ ) to similar degrees $(Z=1.65, p=0.05)$. Employment during caregiving showed a statistically significant difference $(Z=1.65$, $p=0.05)$ : the post baby boomers reported lower levels of burden when they were employed during caregiving; however, baby boomers reported a higher burden during employment.

In addition, few differences in individual factors were reported. First, Hispanic baby boomers reported lower levels of caregiver burden than non-Hispanic Caucasians $(\beta=-0.09, p=0.04)$. Second, relationships between caregivers and care recipients were identified as a significant factor of caregiver burden in the post baby boomer group, but not for baby boomers. Compared to nonfamily caregivers, family caregivers in the post baby boomer group reported higher levels of burden when the care recipient was a spouse, child, or other relative (respectively, $\beta=0.11,0.19$, and 0.12 ; all $p$ values $<0.01$ ). In addition, the post baby boomer group reported higher levels of burden when they took care of both adults and children simultaneously compared to those responsible for adult care recipients only $(\beta=0.11, p<0.01)$.

\section{Discussion}

In this study, caregiving-related factors were more likely to increase burden than sociodemographics, specifically, caregiving without choice and longer hours spent on

Table 2 Caregiving-related characteristics of informal caregivers between the two generational groups

\begin{tabular}{|c|c|c|c|c|c|c|}
\hline Variables & Levels & All (weighted \%) & $\begin{array}{l}\text { Baby boomer } \\
\text { group (weighted \%) }\end{array}$ & $\begin{array}{l}\text { Post baby boomer } \\
\text { group (weighted \%) }\end{array}$ & $x^{2}$ & $p$ value \\
\hline \multirow[t]{2}{*}{ Current caregiving } & Currently providing & 54.87 & 58.74 & 51.66 & 5.26 & 0.02 \\
\hline & Provided in the past 12 months & 45.13 & 41.26 & 48.34 & & \\
\hline \multirow[t]{2}{*}{ Primary caregiving } & Primary provider & 61.10 & 59.07 & 62.79 & 1.50 & 0.23 \\
\hline & Non-primary provider & 38.90 & 40.93 & 37.21 & & \\
\hline \multirow[t]{2}{*}{ Caregiving lack of choice } & Lack of choice & 50.00 & 55.79 & 45.17 & 11.68 & $<0.01$ \\
\hline & Caregiving by choice & 50.00 & 44.21 & 54.83 & & \\
\hline \multirow[t]{2}{*}{ Employed during caregiving } & Employed during caregiving & 68.13 & 62.82 & 72.55 & 11.34 & $<0.01$ \\
\hline & Unemployed during caregiving & 31.87 & 37.18 & 27.45 & & \\
\hline \multirow[t]{2}{*}{ Dual responsibility } & Adult care only & 84.34 & 93.05 & 77.10 & 50.00 & $<0.001$ \\
\hline & Both adult and child care & 15.66 & 6.95 & 22.90 & & \\
\hline
\end{tabular}




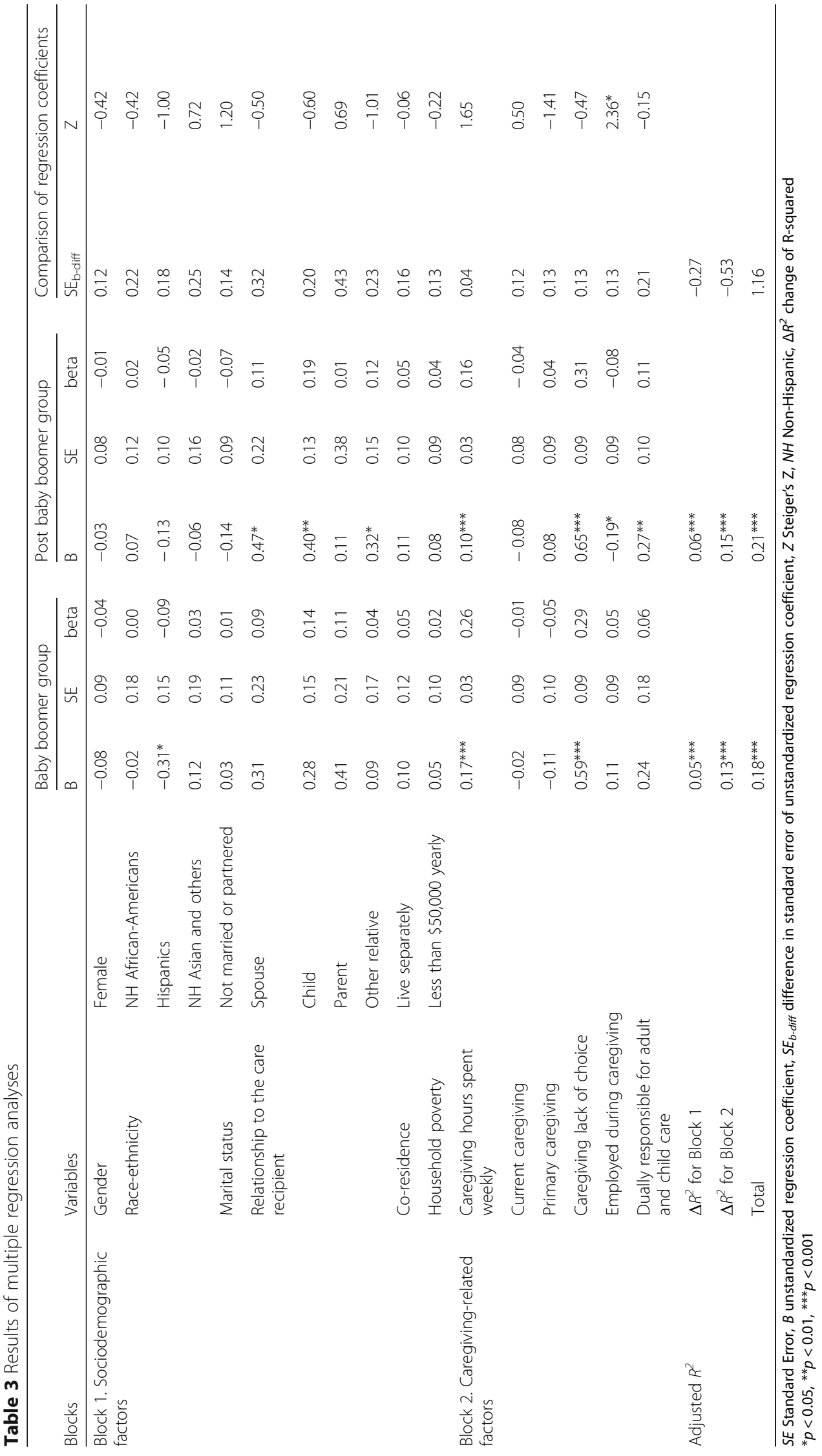


caregiving in both generational groups. However, post baby boomers reported additional challenges during caregiving, such as dual responsibility of both adult and child care, unemployment, and a family relationship with the care recipient.

Caregiving by choice was the most important factor that determined the level of caregiver burden. Taking a caregiving role without choice is considered stressful regardless of the presence of secondary assistants or a coresident situation [10,31]. It is important for caregivers to have the opportunity to voluntarily take on the role after they have considered the benefits in relation to the autonomy and self-determination they would give up by becoming a caregiver [31]. After careful consideration, undecided or potential candidates would take on the caregiving role after evaluating the expected gains and losses to their own future plans [10,32].

Interestingly, our study findings show that the post baby boomers spent significantly less time on caregiving compared to baby boomers. Usually, a greater number of caregiving hours means a more severe medical condition or functional decline in the care recipient, which is considered an increasing factor of caregiving burden $[29,31]$. The use of formal health services among older baby boomers might also influence the time spent on caregiving in the post baby boomer group [33]. However, another study has found no relationship between the number of hours and stress level during caregiving [14]. Further research should use objective methods to measure the actual time spent, rather than relying on self-reporting by caregivers, to examine the unique effect of time spent on each care recipient.

Higher burden of care associated with dual caregiving responsibility was identified in the post baby boomer group. Recently, baby boomers have been moving into the aging population and out of the sandwich generation [7]. Younger caregivers with dual responsibilities are at risk of feeling pressed for time and stressed because of the time management requirements of daily life [7]. However, in our study, the tendency to spend less time on caregiving reflected their time management strategies, in contrast to a previous study, in which caregivers with dual responsibilities spent more time on caregiving [8]. They might be proactive in requesting assistance from secondary caregivers, which decreases time spent on adult care [34]. When considering the higher proportion of dually responsible caregivers in the post baby boomer group, younger caregivers might subtract the time spent on child care from the total time of caregiving because raising children is an expected role in their developmental stage $[8,10]$. Further studies should perform moderation analyses of caregiver burden in those with dual responsibilities, by generational group or resource use, as in a previous study [8].
Unemployment was a unique factor contributing to caregiver burden in the post baby boomer group. The annual income of the post baby boomer caregivers was significantly lower than the baby boomer caregivers, although the majority of both generational groups were likely to be working during caregiving [35]. A previous study reported that the strength of negative impact on caregiving burden varies depending on levels of income [15]. Loss of regular income has been identified as a significant factor in decreasing financial security, livelihood, self-worth, and social interaction [36, 37]. Thus, financial hardships may make the younger group feel vulnerable as part of their caregiver burden.

Post baby boomer caregivers reported a high burden when caring for any family member or relative except their parents. Historically, family members take on caregiver roles as a normative expectation and learn tasks without purposive effort [5]. The predictable demands of child care were relatively acceptable and prepared them for performing specific tasks and roles. However, caring for young spouses and other relatives with diverse healthcare needs was less predictable and more likely to worsen over time across the caregiving trajectory [31, 38]. Many post baby boomer caregivers are raised by a single parent. They may maintain family ties with their parents, but not with other family members or relatives because of changes in marital disruptions, weak family ties, and romantic patterns $[12,13]$.

As the baby boomers have joined the aging population, it is necessary to revisit the current social policy programs that were mostly designed for baby boomer or older caregivers $[39,40]$. In addition, awareness programs should include the importance of voluntary decisions in taking caregiving roles and the ability to balance between gain and loss during caregiving [31, 32]. For vulnerable caregivers, including those who had no choice in taking on their caregiving role and higher-hour caregivers, support to hire paid helpers, access to paid family leave benefits through their employers, cash compensation for their unpaid caregiving hours, and provision of an income tax credit for loss of work hours due to caregiving would be most helpful [2]. A flexible work schedule and employer-sponsored day-care centers for both adult and child care recipients are also helpful for working caregivers [6].

Our study has several limitations. First, the use of cross-sectional data limited the study's ability to make predictive statements about the factors contributing to caregiver burden. Second, we used self-report data obtained from caregivers without information on care recipients. Third, age may affect all other independent variables because the two age groups (baby boomers and post baby boomers) occupy different stages of the life cycle. Future studies could consider dyadic relationships 
between caregivers and care recipients by adding information about the medical conditions of the care recipients. Longitudinal studies need to include validated multiple measures of psychological distress for comprehensive understanding of caregiver burden change over the lifetime within a specific age group.

\section{Conclusion}

This study examined sociodemographic and caregivingrelated characteristics of informal caregivers in the United States and specified factors associated with subjective burden of care in each generational group. By comparing two generational caregiver groups, baby boomers and post baby boomers experience unique agerelated challenges associated with burden of care were identified. Compared to baby boomer group, post baby boomer caregivers are experiencing more time constraint and financial problems that conflict with their other responsibilities at home and work. Our study suggests that it is necessary to develop age-specific caregiving programs and resources tailored to the developmental needs of informal caregivers in different stages of life. In addition, specific vulnerable groups should have priority to receive the benefits of policies, such as those without choice and younger working caregivers.

\section{Abbreviations}

AARP: The American Association of Retired Persons; NAC: National Alliance for Caregiving; $\mathrm{NH}$ : Non-Hispanic

\section{Acknowledgments}

The authors appreciate the generosity of the National Alliance for Caregiving and the American Association of Retired Persons in allowing outside researchers to use their data.

\section{Funding}

This research was supported by Basic Science Research Program through the National Research Foundation of Korea (NRF) funded by the Ministry of Education (NRF-2016R1D1A1B03932013) and Mo-Im Kim Nursing Institute, College of Nursing, Yonsei University.

\section{Availability of data and materials}

The data used in this study are available for scientists at universities and research institutes exclusively for scientific purposes at a free charge. The study data can be obtained from the website: http://www.caregiving.org/ research/open-data/.

\section{Authors' contributions}

All authors critically reviewed the manuscript, provided significant editing of the article, and approved the final manuscript. Each author uniquely contributed in the following specific research steps: HK, design and concept of analyses, supervision during data preparation, statistical analysis and interpretation of data, preparing the manuscript; SL, preparation of data, assisting with statistical analysis and preparing the manuscript; $\mathrm{SH}$, design and concept of analyses and preparing the manuscript; MC, providing statistical validation and interpretation of data; JC, design and concept of analyses and preparing the manuscript.

\section{Ethics approval and consent to participate}

Prior to the interview, written informed consent was given by all participants of the NAC and AARP survey in 2014. The data were anonymized and de-identified with no personal information, with careful protection of confidentiality. The Institutional Review Board of College of Nursing at Yonsei University approved the exempt status prior to the secondary data analysis.

\section{Competing interests}

The authors declare that they have no competing interests.

\section{Publisher's Note}

Springer Nature remains neutral with regard to jurisdictional claims in published maps and institutional affiliations.

\section{Author details}

${ }^{1}$ College of Nursing, Yonsei University, 50-1 Yonsei-ro, Seodaemun-gu, Seoul 03722, Republic of Korea. ${ }^{2}$ Mo-Im Kim Nursing Research Institute, Yonsei University, 50-1 Yonsei-ro, Seodaemun-gu, Seoul 03722, Republic of Korea. ${ }^{3}$ College of Nursing, Sungshin Women's University, 55 Dobong-ro 76ga-gil, Gangbuk-gu, Seoul 01133, South Korea. ${ }^{4}$ Department of Leadership \& Professional Studies, School of Education \& Human Development, College of Arts, Sciences \& Education, Florida International University, 11200 SW 8th St. ZEB 250B, Miami, FL 33199, USA.

Received: 10 October 2017 Accepted: 20 April 2018

Published online: 02 May 2018

\section{References}

1. International Alliance of Carer Organization. IACO 2014-2018 strategic business plan. 2015. http://www.internationalcarers.org/wp-content/ uploads/2015/08/IACO-Strategic-Plan-2014-18-Approved-Jan-2015.pdf. Accessed 4 Jan 2017.

2. National Alliance for Caregiving and the American Association of Retired Persons Public Policy Institute. Caregiving in the U.S. 2015. http://www. caregiving.org/wp-content/uploads/2015/05/2015_CaregivingintheUS_FinalReport-June-4 WEB.pdf. Accessed 18 June 2017.

3. He W, Goodkind D, Kowal P. An aging world: 2015. Washington, DC: U.S. Census Bureau; 2016.

4. MetLife Mature Market Institute (MMMI). The MetLife study of caregiving costs to working caregivers: double jeopardy for baby boomers caring for their parents. New York: Metropolitan Life Insurance Company; 2011.

5. Guberman N, Lavoie JP, Blein L, Olazabal I. Baby boom caregivers: care in the age of individualization. Gerontologist. 2012;52:210-8.

6. DeRigne L, Ferrante $S$. The sandwich generation: a review of the literature Florida. Public Health Rev. 2012;9:95-104.

7. Parker K, Patten E. The sandwich generation: rising financial burdens for middle-aged Americans. Washington, DC: Pew Research Center\& Demographic Trends Projects; 2013.

8. Suh J. Measuring the "sandwich": care for children and adults in the American time use survey 2003-2012. J Fam Econ Iss. 2016;37:197-211.

9. Fingerman KL, Pitzer LM, Chan W, Birditt K, Franks MM, Zarit S. Who gets what and why? Help middle-aged adults provide to parents and grown children. J Gerontol B Psychol Sci Soc Sci. 2011;66:87-98.

10. Hou PY, Lai CK, Chung CS, Sham AK, Yeung CL. Young adults' experiences of their parents caring for a relative with dementia. Geriatr Gerontol Int. 2016;16:873-9.

11. Owram D. Born at the right time: a history of the baby-boom generation. Toronto: University of Toronto Press; 1996

12. Hughes JW, Seneca JJ. America's demographic tapestry: baseline for the new millennium. New Brunswick: Rutgers University Press; 1999.

13. Fingerman $\mathrm{KL}$, Pillemer KA, Silverstein M, Suitor JJ. The baby boomers' intergenerational relationships. Gerontologist. 2012:52:199-209.

14. Hoffman GJ, Lee J, Mendez-Luck CA. Health behaviors among baby boomer informal caregivers. Gerontologist. 2012:52:219-30.

15. Do EK, Cohen SA, Brown MJ. Socioeconomic and demographic factors modify the association between informal caregiving and health in the sandwich generation. BMC Public Health. 2014;14:362.

16. Badley EM, Canizares M, Perruccio AV, Hogg-Johnson S, Gignac MA. Benefits gained, benefits lost: comparing baby boomers to other generations in a longitudinal cohort study of self-rated health. Milbank Q. 2015;93:40-72.

17. Beutell NJ. Generational differences in work-family conflict and synergy. Int J Environ Res Public Health. 2013;10:2544-59.

18. Bastawrous M, Gignac MA, Kapral MK, Cameron JI. Adult daughters providing post-stroke care to a parent: a qualitative study of the impact that role overload has on lifestyle, participation and family relationships. Clin Rehabil. 2015;29:592-600. 
19. Tramonti F, Bongioanni P, Leotta R, Puppi I, Rossi B. Age, gender, kinship and caregiver burden in amyotrophic lateral sclerosis. Psychol Health Med. 2015;20:41-6.

20. Ain QU, Dar NZ, Ahmad A, Munzar S, Yousafzai AW. Caregiver stress in stroke survivor: data from a tertiary care hospital - a cross sectional survey. BMC Psychol. 2014;2:49.

21. Vogler J, Klein AM, Bender A. Long-term health-related quality-of-life in patients with acquired brain injury and their caregivers. Brain Inj. 2014;28: $1381-8$.

22. Cormio C, Romito F, Viscanti G, Turaccio M, Lorusso V, Mattioli V. Psychological well-being and posttraumatic growth in caregivers of cancer patients. Front Psychol. 2014;5:1342

23. Koyama A, Matsushita M, Hashimoto M, Fujise N, Ishikawa T, Tanaka H, Ikeda $M$, et al. Mental health among younger and older caregivers of dementia patients. Psychogeriatrics. 2017;17:108-14

24. Germain V, Dabakuyo-Yonli TS, Marilier S, Putot A, Bengrine-Lefevre L, Arveux P, Manckoundia P, Quipourt V. Management of elderly patients suffering from cancer: assessment of perceived burden and of quality of life of primary caregivers. J Geriatr Oncol. 2017:8:220-8.

25. Ennis E, Bunting BP. Family burden, family health and personal mental health. BMC Public Health. 2013;13:255.

26. National Alliance for Caregiving and the American Association of Retired Persons Public Policy Institute. Caregiving in the U.S. 2015 - appendix B: detailed methodology. 2015. http:/www.caregiving.org/wp-content/ uploads/2015/05/CGV016-Main-Report-Appendix-B-Detailed-Methodology-5. 21.15.pdf. Accessed 4 Jan 2017.

27. Pearlin LI, Mullan JT, Semple SJ, Skaff MM. Caregiving and the stress process: an overview of concepts and their measures. Gerontologist. 1990;30:583-94.

28. DeNavas-Walt C, Proctor BD. Income and poverty in the United States: 2014. Washington, DC: U.S. Census Bureau; 2015.

29. Kim H, Chang M, Rose K, Kim S. Predictors of caregiver burden in caregivers of individuals with dementia. J Adv Nurs. 2012;68:846-55.

30. Paternoster R, Brame R, Mazerolle P, Piquero A. Using the correct statistical test for the equality of regression coefficients. Criminology. 1998;36:859-66.

31. Schulz R, Beach SR, Cook TB, Martire LM, Tomlinson JM, Monin JK. Predictors and consequences of perceived lack of choice in becoming an informal caregiver. Aging Ment Health. 2012:16:712-21.

32. Rohr MK, Lang FR. The role of anticipated gains and losses on preferences about future caregiving. J Gerontol B Psychol Sci Soc Sci. 2016;71:405-14.

33. Robison J, Shugrue N, Fortinsky RH, Gruman C. Long-term supports and services planning for the future: implications from a statewide survey of baby boomers and older adults. Gerontologist. 2014;54:297-313.

34. Rubin RM, White-Means SI. Informal caregiving: dilemmas of sandwiched caregivers. J Fam Econ Iss. 2009;30:252-67.

35. United States Census Bureau. American fact finder. 2016. http://factfinder. census.gov/faces/nav/jsf/pages/searchresults.xhtml?refresh=t\&keepList=f. Accessed 2 Oct 2016.

36. George LK, Blazer DG, Hughes DC, Fowler N. Social support and the outcome of major depression. Br J Psychiatry. 1989;154:478-85.

37. D'Arcy C, Siddique CM. Unemployment and health: an analysis of "Canada health survey" data. Int J Health Serv. 1985;15:609-35.

38. Kaye HS, Harrington C, LaPlante MP. Long-term care: who gets it, who provides it, who pays, and how much? Health Aff. 2010;29:11-21.

39. Lavretsky H, Epel ES, Siddarth P, Nazarian N, Cyr NS, Khalsa DS, Irwin MR. A pilot study of yogic meditation for family dementia caregivers with depressive symptoms: effects on mental health, cognition, and telomerase activity. Int J Geriatr Psychiatry. 2013;28:57-65.

40. Cheng HY, Chair SY, Chau JP. The effectiveness of psychosocial interventions for stroke family caregivers and stroke survivors: a systematic review and meta-analysis. Patient Educ Couns. 2014;95:30-44.

Ready to submit your research? Choose BMC and benefit from:

- fast, convenient online submission

- thorough peer review by experienced researchers in your field

- rapid publication on acceptance

- support for research data, including large and complex data types

- gold Open Access which fosters wider collaboration and increased citations

- maximum visibility for your research: over $100 \mathrm{M}$ website views per year

At BMC, research is always in progress.

Learn more biomedcentral.com/submissions 